\title{
Association between Comorbidities and Selected Sociodemographic Factors with Complications of Diabetes: Results from the National Diabetic Registry Malaysia
}

\author{
Nor Asiah Muhamad1*, Mohd Hatta Abdul Mutalip1, Normi Mustapha², \\ Nor Soleha Mohd Dali' ${ }^{3}$, Tahir Aris ${ }^{1}$, Fatanah Ismail ${ }^{4}$, Shahnaz Murad5, \\ Lokman Hakim Sulaiman' \\ ${ }^{1}$ Institute for Public Health, Ministry of Health Malaysia, Kuala Lumpur, Malaysia \\ ${ }^{2}$ Faculty of Science \& Technology, Open University of Malaysia, Kuala Lumpur, Malaysia \\ ${ }^{3}$ Institute for Medical Research, Ministry of Health Malaysia, Kuala Lumpur, Malaysia \\ ${ }^{4}$ Family Health Development Division, Ministry of Health Malaysia, Putrajaya, Malaysia \\ ${ }^{5}$ Office of Deputy Director General of Health (Research and Technical), Ministry of Health, Putrajaya, Malaysia \\ ${ }^{6}$ Department of Community Medicine, International Medical University, Kuala Lumpur, Malaysia \\ Email: *norasiahdr@gmail.com
}

How to cite this paper: Muhamad, N.A., Mutalip, M.H.A., Mustapha, N., Dali, N.S.M., Aris, T., Ismail, F., Murad, S. and Sulaiman, L.H. (2018) Association between Comorbidities and Selected Sociodemographic Factors with Complications of Diabetes: Results from the National Diabetic Registry Malaysia. Journal of Diabetes Mellitus, 8, 84-97.

https://doi.org/10.4236/jdm.2018.83009

Received: May 26, 2018

Accepted: August 19, 2018

Published: August 22, 2018

Copyright ( 2018 by authors and Scientific Research Publishing Inc. This work is licensed under the Creative Commons Attribution International License (CC BY 4.0).

http://creativecommons.org/licenses/by/4.0/

\section{(c) (i) Open Access}

\begin{abstract}
Background: This study aims to determine the hazard ratio of having any complication from diabetes mellitus, and the associations between comorbidities and risk of having any complications from diabetes mellitus among diabetic patients who have attended government primary care clinics. Methods: Secondary data were retrieved from the Malaysian National Diabetic Registry which included all patients who received care. The data from the study on the socio-demographic, diabetes complications, clinical and treatment characteristics were analyzed using descriptive statistics. Cox regression was performed to estimate the hazard ratio for comorbidities, tobacco use, duration of diabetes and socio-demography characteristics upon time to diabetic complications. Results: Adjusted for other covariates, increase number of comorbidities contributed the highest hazard ratio risk: 1 comorbid (aHR: 2.47, 95\% CI: 2.39, 2.55), 2 comorbidities (aHR: 4.34, 95\% CI: 4.22, 4.47), 3 comorbidities (aHR: 6.56, 95\% CI: 6.31, 6.81) and 4 comorbidities (aHR: 9.13, 95\% CI: $8.20,10.17)$. Other factors: age $>40$ years $(8 \%)$ Malays $(27 \%)$ and smokers $(10 \%)$ have hazard risks to develop diabetic complications. Conclusions: Increase in number of comorbidities will increase the risk of getting diabetes complications. Other factors such as age, gender, race, smoking status and duration of diabetes are also noted to contribute to increase risk for
\end{abstract}


diabetes complications.

\section{Keywords}

Comorbidities, Complications, Diabetes, Primary Care

\section{Introduction}

Diabetes is a major global health problem which has put a strain on the global economy with an estimated budget of US 1.31 trillion globally [1]. WHO reported a consistent incremental trend of global diabetes up to four-fold since 1980 [2]. A recent report by the International Diabetes Federation estimated $8.8 \%$ global prevalence of diabetes or 425 million adults aged 20 to 79 years old are diabetic [3]. The WHO data representing 130 countries indicated 382 million people had diabetes in 2013, and this number is expected to increase up to 592 million by 2035 [2]. The trend of diabetes has been on the rise especially in low and middle-income countries [3] [4] with $84.5 \%$ of undiagnosed diabetes which will increase the number of diabetic cases in the future [3]. Diabetes can lead to complications that significantly impact the quality of life and causes premature mortality [4]. WHO estimated 3.7 million burden of deaths attributable to high blood glucose which includes 1.5 million diabetes deaths and additional 2.2 million deaths of other complications associated with high blood glucose level among upper middle income and low income countries [4].

The rise in diabetes prevalence has been attributed to numerous factors, including population growth and ageing [5]. Other factors, such as obesity and physical inactivity, have also contributed substantially to the global diabetes burden. Thus, preventing these factors can prevent or delay the onset of type 2 diabetes [5] [6]. Several studies have also documented clinical evidence of multiple comorbidities which will increase the risk of diabetes complication and complicate diabetes management [7] [8]. Comorbidities also increase the burden of medical expenditure and care for patients with diabetes and other range of complications for treatment [9] [10]. Other study also indicates lower utilization of specialist care has been proven to contribute an increased risk of diabetes complications [11].

In Malaysia, the recently published population-based survey of National Health and Morbidity Survey 2015 indicates 17.5\% of known and undiagnosed diabetes among adults aged 18 years and above [12]. The survey also revealed an incremental trend in diabetes prevalence from 5.5\% among adults aged 18 to 19 years and peaks in older age [12]. Recent findings in Malaysia recruited patients from general hospitals, diabetes clinics and referral clinics reported high burden of diabetic patients with uncontrolled coexisted complications [13]. The study also found worsening glycemic control with multiple comorbidities despite of adherence to medication [13]. Another studies utilized a cohort of diabetes patients attended primary health care clinic in Malaysia reported high burden of 
comorbidities especially in hypertension and complications associated with diabetes [14] [15].

Numerous studies have been conducted to investigate factors associated with diabetes complications [9] [16]. There were several studies in Malaysia documented types of diabetes complications [13] and medication adherence [13] [17]. However, based on our current knowledge, none of the studies measure time factor or duration of diabetes to the development of the complications associated with diabetes. Hence, we feel the necessity to further explore the risk of these coexisted conditions with other predictors by considering the time factor to developing diabetes-associated complications. Understanding on these coexisted conditions and other factors is important for health care practitioners especially at the primary health care setting to manage diabetic patient more effectively. This information is also essential for the primary health care provider to improve the quality of care and outcomes of diabetic patient to inhibit complications and reduce the burden of chronic or secondary care as a result of diabetes complication. Therefore, this study aims to determine the hazard factors of having any complication from diabetes mellitus, and its association with comorbidities among diabetes patients attended government primary health care clinics by utilizing data from the Malaysian National Diabetic Registry.

\section{Methods}

\subsection{Data Collection}

Data for this study was obtained from the National Diabetes Registry (NDR). The NDR routinely records information on patients with diabetes mellitus (DM) managed by participating Ministry of Health (MOH) health clinics since 2009. It consists of two related components, namely, the patient registry and clinical audit dataset. The audit dataset is a subset of the patient registry. On an annual basis, a proportion of patients from the registry are randomly selected for auditing of clinical variables and clinical outcomes and they are added to their registry record [15].

In all $\mathrm{MOH}$ health clinics, diabetes mellitus is diagnosed based on the plasma glucose criteria either fasting plasma glucose (FPG) or 2-hour plasma glucose (2-h PG) value after a 75-g oral glucose tolerance test (OGTT) or the A1C criteria. The cut-off point for FPG is $126 \mathrm{mg} / \mathrm{dL}(7.0 \mathrm{mmol} / \mathrm{L})$, for $2-\mathrm{h}$ PG is 200 $\mathrm{mg} / \mathrm{dL}(11.1 \mathrm{mmol} / \mathrm{L})$ and for $\mathrm{A} 1 \mathrm{C}$ is $6.3 \%(45 \mathrm{mmol} / \mathrm{mol})$. A diagnosis of diabetes mellitus is confirmed when the results for any of the two tests mentioned earlier are beyond the threshold [18].

\subsection{Site Selection Criteria}

There are currently 1061 health clinics managing patients with DM. However, for this study we selected 963 participating health clinics throughout the country that provided complete data of diabetic patients to NDR. These 963 clinics were also chosen because these clinics participated in the NDR database project that compiled complete information of patients with DM in primary health care set- 
ting. Health clinics which did not participate in the NDR database system were excluded from this study.

\subsection{Patient Selection Criteria}

The registry includes all patients with DM managed at the participating health clinics. These patients came with any type of DM namely Type 1 DM (T1DM), Type 2 DM (T2DM), and other types of DM, such congenital diabetes, cystic fibrosis-related diabetes, steroid-related diabetes that is induced by high doses of glucocorticoids, and several forms of monogenic diabetes. For the purpose of this study, only patients with T1DM and T2DM were included. Additional inclusion criteria were DM patients aged between 20 - 70 years old, diagnosed from year 1990 and above, with information of comorbidities; ischemic heart disease, cerebrovascular disease, hypertension and dyslipidemia. All patients with missing date of diagnosis and complications related to DM were excluded. A total of 729,743 patients were identified from the registry. Of these, 567,442 were included in the final analysis. All data were de-identified prior to analysis. This study was registered under the Malaysia National Medical Research Registry (NMRR) with the identification number NMRR-17-33234334 and funded by $\mathrm{MOH}$. The Malaysian guideline permits the use of secondary data from the registry if the data are anonymised. Hence, the data were de-identified prior to analysis.

\subsection{Statistical Analysis}

Analysis was performed to determine the distributions of socio-demographic factors, diabetes complications, namely, retinopathy, nephropathy, diabetic foot ulcer and amputation, and number of comorbidities. For all cases with diagnosis dates (diagnosed since 1 January 1990), the Cox proportional hazard model was performed to calculate crude and multivariable-adjusted hazard ratios (HRs) in the model with the variables; smoking status, type and duration of diabetes, and number of comorbidities. Time was defined as diagnosis date to time of complications; retinopathy, nephropathy, diabetic foot ulcer and amputation. Time periods were defined as less than five years, five to ten years and more than ten years. All analyses were performed using Stata SE 12.1 software. All reported $p$-values were 2 -sided, and $p<0.05$ indicates a significant difference.

\section{Results}

During the study period, a total of 567,442 patients with mean age of 56.59 (SD 9.38) years met the inclusion criteria. About $57 \%(325,361)$ were females and more than $60 \%$ were Malays. A majority of the patients were nonsmokers (80.5\%). The demographic characteristics of the respondents are presented in Table 1.

Clinical characteristics showed that almost $100 \%(564,140)$ of the patients were T2DM with a mean disease duration of 7.14 (SD4.90) years. With regards to comorbidities, almost $65 \%(365,765)$ had been diagnosed with hypertension, $55 \%(312,260)$ with dyslipidaemia, $4 \%$ ischemic heart disease and $1 \%$ 
Table 1. Demographic characteristics $(\mathrm{N}=567,442)$.

\begin{tabular}{cccccc}
\hline \multicolumn{1}{c}{ Characteristics } & Retinopathy & Nephropathy & $\begin{array}{c}\text { Diabetic Foot } \\
\text { Ulcer }\end{array}$ & Amputation \\
\hline \multicolumn{1}{c}{$\mathbf{N}(\%)$} & $\mathbf{n}(\%)$ & $\mathbf{n}(\%)$ & $\mathbf{n}(\%)$ & $\mathbf{n}(\%)$ \\
\hline Age group & & & & & \\
\hline$\leq 40$ & $37,602(6.63)$ & $1116(2.97)$ & $1263(3.36)$ & $258(0.69)$ & $113(0.30)$ \\
$>40$ & $529,840(93.37)$ & $35,321(6.42)$ & $38,281(7.23)$ & $6355(1.20)$ & $3419(0.65)$ \\
\hline Gender & & & & & \\
\hline Male & $242,081(42.66)$ & $15,069(6.22)$ & $18,273(7.55)$ & $3345(1.38)$ & $1852(0.77)$ \\
Female & $325,361(57.34)$ & $21,368(6.57)$ & $21,271(6.54)$ & $3268(1.00)$ & $1680(0.52)$ \\
\hline Race & & & & & \\
\hline Malay & $358,577(63.19)$ & $22,656(6.32)$ & $28,062(7.83)$ & $4855(1.35)$ & $2508(0.70)$ \\
Chinese & $92,726(16.34)$ & $6394(6.90)$ & $5723(6.17)$ & $653(0.70)$ & $400(0.43)$ \\
Indian & $73,874(13.02)$ & $4314(5.84)$ & $4153(5.62)$ & $820(1.11)$ & $490(0.66)$ \\
Others & $42,265(7.45)$ & $3073(7.27)$ & $1606(3.80)$ & $285(0.67)$ & $134(0.32)$ \\
\hline Smoking & & & & & \\
status & & & & & \\
\hline Yes & $31,999(5.64)$ & $2239(7.00)$ & $2752(8.60)$ & $6612(1.17)$ & $320(0.62)$ \\
No & $456,485(80.45)$ & $29,509(6.46)$ & $31,447(6.89)$ & $5088(1.11)$ & $2755(0.60)$ \\
Not known & $78,958(13.91)$ & $4673(5.93)$ & $5326(6.76)$ & $892(1.13)$ & $456(0.58)$ \\
\hline & & & & & \\
\hline & & & & & \\
\hline
\end{tabular}

cerebrovascular disease. For each of these comorbidities, the proportion unknown ranged between $4.3 \%$ to $8.5 \%$. In terms of complications, $7 \%(39,544)$ of the patients have nephropathy followed closely by retinopathy $6.42 \%(36,437)$, diabetic foot ulcer $1.17 \%$ (6613) and amputation $0.62 \%$ (3532). A minority comprising $0.04 \%$ (222) diabetic patients have all four complications as depicted in Table 2.

Table 3 shows the Cox proportional hazard model on the risk of having any complication, such as retinopathy, nephropathy and diabetic foot ulcer with multivariable-adjusted hazard ratios (HRs) for selected socio-demographic data, duration of diabetes, smoking, and number of comorbidities.

Age $>40$ years was significantly related to slightly higher risk of complications with an adjusted HR of 1.08 (95\% CI; 1.04, 1.13) while female had lower risk with HR of 0.87 (95\% CI; $0.86,0.88)$ respectively. Malay ethnicity was significantly associated with having a significantly higher risk of any complication with adjusted HR of 1.27 (95\% CI; 1.25, 1.30). Diabetic patients who smoke were also found to be associated with having complications with adjusted HR of 1.10 (95\% CI; 1.07, 1.14). Compared to under-five years' disease duration, longer periods were significantly associated with a progressively lower risk of complications (aHR 0.91; 95\% CI 0.89, 0.93 for 5 - 10 years and 0.67; 95\% CI 0.66, 0.69 for $>10$ years). As for the number of comorbidities, the associated risk significantly 
Table 2. Clinical characteristics $(\mathrm{N}=567,442)$.

\begin{tabular}{|c|c|c|}
\hline Characteristics & $\mathbf{N}$ & $\%$ \\
\hline \multicolumn{3}{|l|}{ Type of diabetes } \\
\hline Type 1 & 3302 & 0.58 \\
\hline Type 2 & 564,140 & 99.42 \\
\hline \multicolumn{3}{|c|}{ Duration of diabetes (year) } \\
\hline Mean(SD) & \multicolumn{2}{|c|}{$7.14(4.90)$} \\
\hline$<5$ & 200,666 & 35.36 \\
\hline $5-10$ & 237,419 & 41.84 \\
\hline$>10$ & 129,357 & 22.80 \\
\hline \multicolumn{3}{|l|}{ Ischemic heart disease } \\
\hline Yes & 22,285 & 3.93 \\
\hline No & 496,941 & 87.58 \\
\hline Not known & 48,216 & 8.50 \\
\hline \multicolumn{3}{|c|}{ Cerebrovascular disease } \\
\hline Yes & 6332 & 1.12 \\
\hline No & 516,033 & 90.94 \\
\hline Not known & 45,077 & 7.94 \\
\hline \multicolumn{3}{|l|}{ Hypertension } \\
\hline Yes & 365,765 & 64.46 \\
\hline No & 177,308 & 31.25 \\
\hline Not known & 24,369 & 4.29 \\
\hline \multicolumn{3}{|l|}{ Dyslipidaemia } \\
\hline Yes & 312,260 & 55.03 \\
\hline No & 224,729 & 39.60 \\
\hline Not known & 30,453 & 5.37 \\
\hline \multicolumn{3}{|l|}{ Complication } \\
\hline Retinopathy & 36,437 & 6.42 \\
\hline Nephropathy & 39,544 & 7.00 \\
\hline Diabetic foot ulcer & 6613 & 1.17 \\
\hline Amputation & 3532 & 0.62 \\
\hline All the above & 222 & 0.04 \\
\hline
\end{tabular}

increased with increasing number of comorbidities from aHR 2.47 (95\% CI 2.39, 2.55 ) for one comorbidity to 9.13 (95\% CI 8.20, 10.17) for patients with 4 comorbidities (Table 3). 
Table 3. Cox Proportional Hazard Ratio analysis to determine hazard of having any complication $(\mathrm{N}=567,442)$.

\begin{tabular}{|c|c|c|c|c|}
\hline Factors & $\mathbf{n}$ & Hazard ratio & $95 \% \mathrm{CI}$ & $p$-value \\
\hline \multicolumn{5}{|l|}{ Age group } \\
\hline$\leq 40$ (ref) & 37,602 & 1.00 & & \\
\hline$>40$ & 529,840 & 1.08 & $1.04,1.13$ & $<0.001$ \\
\hline \multicolumn{5}{|l|}{ Gender } \\
\hline Male (ref) & 242,081 & 1.00 & & \\
\hline Female & 325,361 & 0.87 & $0.86,0.88$ & $<0.001$ \\
\hline \multicolumn{5}{|l|}{ Race } \\
\hline Chinese (ref) & 92,726 & 1.00 & & \\
\hline Malay & 358,577 & 1.27 & $1.25,1.30$ & $<0.001$ \\
\hline Indian & 73,874 & 0.96 & $0.93,0.99$ & 0.005 \\
\hline Others & 42,265 & 1.05 & $1.01,1.08$ & 0.011 \\
\hline \multicolumn{5}{|c|}{ Smoking status } \\
\hline${ }^{*} \mathrm{No}$ (ref) & 535,443 & 1.00 & & \\
\hline Yes & 31,999 & 1.10 & $1.07,1.14$ & $<0.001$ \\
\hline \multicolumn{5}{|c|}{ Type of diabetes } \\
\hline Type 1 (ref) & 3302 & 1.00 & & \\
\hline Type 2 & 564,140 & 0.92 & $0.83,1.02$ & 0.110 \\
\hline \multicolumn{5}{|c|}{ Duration of diabetes (year) } \\
\hline$<5$ (ref) & 200,666 & 1.00 & & \\
\hline $5-10$ & 237,419 & 0.91 & $0.89,0.93$ & $<0.001$ \\
\hline$>10$ & 129,357 & 0.67 & $0.66,0.69$ & $<0.001$ \\
\hline \multicolumn{5}{|c|}{ "Number of comorbidity } \\
\hline 0 & 136,983 & 1.00 & & \\
\hline 1 & 174,970 & 2.47 & $2.39,2.55$ & $<0.001$ \\
\hline 2 & 235,632 & 4.34 & $4.22,4.47$ & $<0.001$ \\
\hline 3 & 19,020 & 6.56 & $6.31,6.81$ & $<0.001$ \\
\hline 4 & 837 & 9.13 & $8.20,10.17$ & $<0.001$ \\
\hline
\end{tabular}

Notes: *No indicates "No" and "Not known" categories. Reference category $=1.00$. Backward stepwise method was applied. ${ }^{*}$ Comorbidities; ischemic heart disease, cerebrovascular disease, hypertension and dyslipidemia; Complications; retinopathy, nephropathy and diabetic foot ulcer.

\section{Discussion}

The present study examined the hazard factors affecting the risk of developing complications in diabetic patients from the NDR registry. These were nephropathy, retinopathy, diabetic foot ulcer, amputation, and combination of all four complications. In this large primary care clinic attendance database, our study 
showed that the presence of comorbidity especially patients with more comorbidities, smoking, older age ethnicity had increased risk of diabetic complications at any time during the follow up from this study.

Our study found an incremental risk of complications with the increasing number of comorbidities. Studies reported the preponderance of diabetes patients with one comorbidity as compared to multiple comorbidities [19] [20] and the presence of comorbidity was significantly associated with diabetic complications [20] [21]. Hypertension, hyperlipidemia and obesity were the commonest comorbidity and about $20 \%$ had the secoexisted comorbidities [20]. It was also reported an incremental trend of obesity correlates with the rise of diabetes especially in T2DM [22].

Several studies reported hypertension was the commonest comorbidity among diabetic patients and the findings are consistent with the present study where 64.5\% patients had coexisted hypertension [7] [19] [23] [24]. In India, hypertension was the most frequent comorbid among T2DM patients living in urban area [7]. Hypertension has been identified as an important risk factor for nephropathy and increases the risk of macrovascular and microvascular complications, which require multifactorial medication for effective treatment [8]. The results from other studies have proven that older people are more likely to present with cardiovascular complications, higher rates of comorbid conditions, mortality, and geriatric syndromes than elderly without diabetes [19]. Generally, the incidence and prevalence of diabetes due to obesity and aging population attributable to $15 \%$ increment in health care expenditure by 2031 [25].

In this study, nephropathy and retinopathy were more prevalent as compared to other complications and this finding concurs with other studies [16] [24]. Retinopathy was found to be a constant complication in diabetes patients [16] and all these complications were more predominant among older age [16]. Among all the complications, neuropathy and nephropathy were the commonest combined complications [16]. According to Donate-Correa et al. [26], one third of diabetic patients are affected by diabetic nephropathy indicates significant of social and economic burdens that could lead to the chronic of end-stage renal disease [27]. A patient with early nephropathy has two times higher risk of retinopathy while a patient with advanced nephropathy has six times higher risk of retinopathy [28]. A study reported that predictive factors for neuropathy include duration of diabetes, retinopathy, $\mathrm{HbA1C}$ at second visit, and creatinine clearance on third visit [29]. Other diabetic complication such as end stage renal disease (ESRD) has shown significant predictor with diabetes-associated mortality adjusted for socioeconomic status [30]. Other study has documented neuropathy as the most predominant complication among diabetic patients [16] especially among Asian patients [31].

In this study, the percentage of diabetic foot ulcer (DFU) was lower than nephropathy and retinopathy. Though it was lower than the global prevalence, DFU causes the highest number of hospital admissions along with considerable costs [3]. This complication includes longer lengths of hospital stay, higher hos- 
pital costs and higher mortality rates as compared to hospitalized diabetes patients without foot-related complications [32] [33]. About 15\% of DM patients will experience a foot ulcer at some point in their life [34] and the mortality risk increases by 2.4-fold over diabetic patients without ulcers [35].

Amputation was among the less observed complication in this study. Finding from a population-based study in Malaysia reported $4.3 \%$ of people with known diabetes reported of lower limb amputations [36]. However, those findings contradicted with this study where less than $1 \%$ of patients underwent leg amputation. According to Goodney et al. the highest risk for amputation are those with persistent hypertension and obesity, poor care delivery in remote settings, and poor engagement in health care systems [37]. Moreover, other study documented more evidence that amputation have contributed to the largest changes in quality of life of diabetic patients besides stroke and loss of vision [38].

Numerous studies discussed age as a strong independent predictor for diabetes and comorbidity [7] [24]. Evidently, multiple comorbidities are more prevalent among older people [24] and types of diabetic-associated complications [16] [19]. Those findings coincide with our finding where older patients ( $>40$ years old) are more prone with diabetes complications. Hypertension and hyperlipidemia are more common among older patients with T2DM compared to younger age [19]. Thus, management of older diabetic patients with multi comorbidities could reduce mortality associated with diabetes complication [3].

Our study found being female is a protective factor for having any complications. This finding supports other studies, as males tend to increase comorbidity burden, which consequently impact further diabetic-related complications [19] [33]. It is well known that cigarette smoking increases the risk of developing diabetes [30]. Smoking is also more prevalent among males in this study and this condition consequently contributed to higher risk of diabetic-associated complications among males. Numerous studies have documented the impact of smoking to diabetes and consequent diabetes complications and smoking also significantly exacerbates diabetic nephropathy in T2DM patients [39].

Our study found Malays and other ethnics had increased risk for diabetes complications and Indians had lower risk for diabetic complication adjusted for other covariates. This situation might be attributable to other predisposes risk factor such as BMI where the Malays were more prone to obesity and other metabolic syndrome that coexist with diabetes [30]. One review highlighted high rates of diabetes among Asian population attributable to high prevalence of obesity which is more common in developing countries [30]. As compared to western countries, Asian people are more prone to abdominal obesity and low muscle mass with increased insulin resistance and the waist circumference reflecting central obesity substantially increased the risk of developing T2DM [30] [31]. Obese patients were more likely to develop diabetic retinopathy such in Indian population and those with central obesity are associated with two times more likely to develop diabetic retinopathy [40].

Our study found duration of diabetes of more than 5 years was significantly 
protective for diabetic complications. This is contradicting with other studies as patients with comorbidities typically had longer diabetes duration, high HbAlc [13] [41] and increased the odds of diabetic complications [3] [13]. This conflicting finding might be associated with our sample population as we only included patients attended primary health care clinics. Primary care services provide multidisciplinary and extensive diabetic care with continuous monitoring to reduce further complications [22] as compared to patients with uncontrolled chronic diabetic with high rate of complications from the hospital [42]. This is further supported by data where about 1.1 million of diagnosed diabetes patients in Malaysia received treatment at primary health care for early prevention of diabetes complications [22] and patients with more comorbidity tended to have more frequent clinic visit than patients with no documented comorbidities [20].

\subsection{Recommendations}

Health care workers assessing diabetic patients are recommended to establish health risk-assessment tools that include comorbidities and lifestyle assessment for use in primary clinical care setting for prevention strategies of diabetes complications. It is vital to increase awareness among the public about the constellation of diseases related to having diabetes and its associated morbidities and mortality risks. Lifestyle management is essential to regulate blood glucose include physical activity and sleeping pattern [6]. Other study also reported counseling for diabetic patients to modify their diet such as glycemic control has significant cost saving through control of complications associated with T2DM [43].

\subsection{Limitations}

NDR data only collect information of diabetic patients attending government primary health care clinics in Malaysia and they do not include patients attending secondary and tertiary government hospital care and private healthcare either general practitioner or private hospitals [15]. These data also rely on the quality of documentation from the primary health care clinics and we anticipate incomplete information from certain variables in the NDR that reduce sample population in our analysis.

\section{Conclusions}

Among all factors, increase in number of comorbidities will increase the risk of diabetes complications. Age, gender, race, smoking status, duration of diabetes and the number of comorbidities (ischemic heart disease, cerebrovascular disease, hypertension and dyslipidemia) are the hazard factors of having any complications to the patients. Older age and male gender are more likely to have the hazard or risk for complication.

\section{Acknowledgements}

We thank the Director General of Health, Ministry of Health, Malaysia for 
permission to publish this report. We also thank Dr. Rozlan Ishak and Dr. Feisul Idzwan Mustapha for their continuous support and assistance. Our appreciation goes to everybody in Non-Communicable Disease Section, Disease Control Division, Ministry of Health, Malaysia.

\section{Funding}

This work was supported by the Ministry of Health Malaysia.

\section{Conflicts of Interest}

The authors declare no conflicts of interest regarding the publication of this paper.

\section{References}

[1] Bommer, C., Heesemann, E., Sagalova, V., Manne-Goehler, J., Atun, R., Bärnighausen, T. and Vollmer, S. (2017) The Global Economic Burden of Diabetes in Adults Aged 20 - 79 Years: A Cost-of-Illness Study. The Lancet Diabetes \& Endocrinology, 5, 423-430. https://doi.org/10.1016/S2213-8587(17)30097-9

[2] WHO (2017) Diabetes.

[3] Federation, I.D. (2017) IDF Diabetes Atlas 2017. International Diabetes Federation, Brussels, 150.

[4] WHO (2016) Global Report on Diabetes.

[5] N.R.F. Collaboration (2016) Worldwide Trends in Diabetes since 1980: A Pooled Analysis of 751 Population-Based Studies with 4.4 Million Participants. The Lancet, 387, 1513-1530. https://doi.org/10.1016/S0140-6736(16)00618-8

[6] A.D. Association (2016) American Diabetes Association Releases 2017 Standards of Medical Care in Diabetes. Comprehensive, Annual Guide Includes New and Updated Recommendations to Safeguard the Physical and Psychological Health of People with Diabetes. American Diabetes Association, Arlington, Virginia.

[7] Pati, S. and Schellevis, F. (2017) Prevalence and Pattern of Co-Morbidity among Type 2 Diabetics Attending Urban Primary Healthcare Centers at Bhubaneswar (India). PloS ONE, 12, e0181661. https://doi.org/10.1371/journal.pone.0181661

[8] Long, A.N. and Dagogo-Jack, S. (2011) Comorbidities of Diabetes and Hypertension: Mechanisms and Approach to Target Organ Protection. The Journal of Clinical Hypertension, 13, 244-251. https://doi.org/10.1111/j.1751-7176.2011.00434.x

[9] Pagano, E., De Rosa, M., Rossi, E., Cinconze, E., Marchesini, G., Miccoli, R., Vaccaro, O., Bonora, E. and Bruno, G. (2016) The Relative Burden of Diabetes Complications on Healthcare Costs: The Population-Based CINECA-SID ARNO Diabetes Observatory. Nutrition, Metabolism and Cardiovascular Diseases, 26, 944-950. https://doi.org/10.1016/j.numecd.2016.05.002

[10] Struijs, J.N., Baan, C.A., Schellevis, F.G., Westert, G.P. and van den Bos, G.A. (2006) Comorbidity in Patients with Diabetes Mellitus: Impact on Medical Health Care Utilization. BMC Health Services Research, 6, 84. https://doi.org/10.1186/1472-6963-6-84

[11] Zgibor, J.C., Songer, T.J., Kelsey, S.F., Drash, A.L. and Orchard, T.J. (2002) Influence of Health Care Providers on the Development of Diabetes Complications. Diabetes Care, 25, 1584-1590. https://doi.org/10.2337/diacare.25.9.1584 
[12] I.f.P. Health, National Health and Morbidity Survey 2015 (NHMS) 2015) Cardiovascular Diseases. Diabetes Institute for Public Health, Kuala Lumpur.

[13] Mafauzy, M., Hussein, Z. and Chan, S. (2011) The Status of Diabetes Control in Malaysia: Results of Diabetes Care 2008. Medical Journal of Malaysia, 66, 175-181.

[14] Chew, B.-H., Lee, P.-Y., Cheong, A.-T., Ismail, M., Shariff-Ghazali, S. and Goh, P.-P. (2016) Messages from the Malaysian Diabetes Registries on Diabetes Care in Malaysian Public Healthcare Facilities. Primary Care Diabetes, 10, 383-386. https://doi.org/10.1016/j.pcd.2016.07.003

[15] Feisul, M.I. and Azmi, S. (Eds.) (2013) National Diabetes Registry Report, 2009-2012. Volume 1, Ministry of Health Malaysia, Kuala Lumpur.

[16] Jelinek, H.F., Osman, W.M., Khandoker, A.H., Khalaf, K., Lee, S., Almahmeed, W. and Alsafar, H.S. (2017) Clinical Profiles, Comorbidities and Complications of Type 2 Diabetes Mellitus in Patients from United Arab Emirates. BMJ Open Diabetes Research and Care, 5, e000427. https://doi.org/10.1136/bmjdrc-2017-000427

[17] Ahmad, N.S., Ramli, A., Islahudin, F. and Paraidathathu, T. (2013) Medication Adherence in Patients with Type 2 Diabetes Mellitus Treated at Primary Health Clinics in Malaysia. Patient Preference and Adherence, 7, 525.

[18] Ministry of Health Malaysia (2015) Clinical Practice Guidelines: Management of Type 2 Diabetes Mellitus. Ministry of Health Malaysia, Putrajaya, 141.

[19] Iglay, K., Hannachi, H., Joseph Howie, P., Xu, J., Li, X., Engel, S.S., Moore, L.M. and Rajpathak, S. (2016) Prevalence and Co-Prevalence of Comorbidities among Patients with Type 2 Diabetes Mellitus. Current Medical Research and Opinion, 32, 1243-1252. https://doi.org/10.1185/03007995.2016.1168291

[20] Lin, P.-J., Kent, D.M., Winn, A., Cohen, J.T. and Neumann, P.J. (2015) Multiple Chronic Conditions in Type 2 Diabetes Mellitus: Prevalence and Consequences. The American Journal of Managed Care, 21, e23-e34.

[21] Kayode, O.O., Odukoya, O.O., Odeniyi, I.A., Olopade, O.B. and Fasanmade, O.A. (2015) Pattern of Complications and Comorbidities among Diabetic Patients in a Tertiary Healthcare Center in Nigeria. Journal of Clinical Sciences, 12, 29. https://doi.org/10.4103/1595-9587.160765

[22] Hussein, Z., Taher, S.W., Gilcharan Singh, H.K. and Chee Siew Swee, W. (2015) Diabetes Care in Malaysia: Problems, New Models, and Solutions. Annals of Global Health, 81, 851-862. https://doi.org/10.1016/j.aogh.2015.12.016

[23] Mastura, I., Chew, B.H., Lee, P.Y., Cheong, A.T., Sazlina, S.G., Jamaiyah, H., Alwi, S.A.R.S., Wahyu, T.S. and Zaiton, A. (2011) Control and Treatment Profiles of 70,889 Adult Type 2 Diabetes Mellitus Patients in Malaysia-A Cross Sectional Survey in 2009. International Journal of Collaborative Research on Internal Medicine \& Public Health, 3, 98-113.

[24] Pantalone, K.M., Hobbs, T.M., Wells, B.J., Kong, S.X., Kattan, M.W., Bouchard, J., Yu, C., Sakurada, B., Milinovich, A. and Weng, W. (2015) Clinical Characteristics, Complications, Comorbidities and Treatment Patterns among Patients with Type 2 Diabetes Mellitus in a Large Integrated Health System. BMJ Open Diabetes Research and Care, 3, e000093. https://doi.org/10.1136/bmjdrc-2015-000093

[25] Alhowaish, A.K. (2013) Economic Costs of Diabetes in Saudi Arabia. Journal of Family \& Community Medicine, 20, 1. https://doi.org/10.4103/2230-8229.108174

[26] Donate-Correa, J., Martín-Núñez, E., Muros-de-Fuentes, M., Mora-Fernández, C. and Navarro-González, J.F. (2015) Inflammatory Cytokines in Diabetic Nephropathy. Journal of Diabetes Research, 2015, Article ID: 948417. https://doi.org/10.1155/2015/948417 
[27] Atkins, R.C. (2005) The Epidemiology of Chronic Kidney Disease. Kidney International, 67, S14-S18. https://doi.org/10.1111/j.1523-1755.2005.09403.x

[28] Rani, P.K., Raman, R., Gupta, A., Pal, S.S., Kulothungan, V. and Sharma, T. (2011) Albuminuria and Diabetic Retinopathy in Type 2 Diabetes Mellitus Sankara Nethralaya Diabetic Retinopathy Epidemiology and Molecular Genetic Study (SN-DREAMS, Report 12). Diabetology \& Metabolic Syndrome, 3, 9. https://doi.org/10.1186/1758-5996-3-9

[29] Abougalambou, S.S.I. and Abougalambou, A.S. (2012) Explorative Study on Diabetes Neuropathy among Type II Diabetic Patients in Universiti Sains Malaysia Hospital. Diabetes \& Metabolic Syndrome: Clinical Research \& Reviews, 6, 167-172. https://doi.org/10.1016/j.dsx.2012.09.002

[30] Chan, J.C., Malik, V., Jia, W., Kadowaki, T., Yajnik, C.S., Yoon, K.-H. and Hu, F.B. (2009) Diabetes in Asia: Epidemiology, Risk Factors, and Pathophysiology. JAMA, 301, 2129-2140. https://doi.org/10.1001/jama.2009.726

[31] Ramachandran, A., Ma, R.C.W. and Snehalatha, C. (2010) Diabetes in Asia. The Lancet, 375, 408-418.

[32] Lazzarini, P.A., O’Rourke, S.R., Russell, A.W., Derhy, P.H. and Kamp, M.C. (2015) Reduced Incidence of Foot-Related Hospitalisation and Amputation amongst Persons with Diabetes in Queensland, Australia. PLoS ONE, 10, e0130609. https://doi.org/10.1371/journal.pone.0130609

[33] Zhang, P., Lu, J., Jing, Y., Tang, S., Zhu, D. and Bi, Y. (2017) Global Epidemiology of Diabetic Foot Ulceration: A Systematic Review and Meta-Analysis. Annals of Medicine, 49, 106-116. https://doi.org/10.1080/07853890.2016.1231932

[34] Deshpande, A.D., Harris-Hayes, M. and Schootman, M. (2008) Epidemiology of Diabetes and Diabetes-Related Complications. Physical Therapy, 88, 1254-1264. https://doi.org/10.2522/ptj.20080020

[35] Goodridge, D., Trepman, E. and Embil, J.M. (2005) Health-Related Quality of Life in Diabetic Patients with Foot Ulcers: Literature Review. Journal of Wound Ostomy \& Continence Nursing, 32, 368-377. https://doi.org/10.1097/00152192-200511000-00007

[36] Letchuman, G., Wan Nazaimoon, W., Wan Mohamad, W., Chandran, L., Tee, G., Jamaiyah, H., Isa, M., Zanariah, H., Fatanah, I. and Ahmad Faudzi, Y. (2010) Prevalence of Diabetes in the Malaysian National Health Morbidity Survey III 2006. Medical Journal of Malaysia, 65, 180-186.

[37] Goodney, P.P., McClurg, A., Spangler, E.L., Brooke, B.S., DeMartino, R.R., Stone, D.H. and Nolan, B.W. (2014) Preventive Measures for Patients at Risk for Amputation from Diabetes and Peripheral Arterial Disease. Diabetes Care, 37, e139-e140. https://doi.org/10.2337/dc14-0034

[38] Hayes, A., Arima, H., Woodward, M., Chalmers, J., Poulter, N., Hamet, P. and Clarke, P. (2016) Changes in Quality of Life Associated with Complications of Diabetes: Results from the Advance Study. Value in Health, 19, 36-41.

https://doi.org/10.1016/j.jval.2015.10.010

[39] Chang, S.A. (2012) Smoking and Type 2 Diabetes Mellitus. Diabetes \& Metabolism Journal, 36, 399-403. https://doi.org/10.4093/dmj.2012.36.6.399

[40] Raman, R., Vaitheeswaran, K., Vinita, K. and Sharma, T. (2011) Is Prevalence of Retinopathy Related to the Age of Onset of Diabetes? Sankara Nethralaya Diabetic Retinopathy Epidemiology and Molecular Genetic Report No. 5. Ophthalmic Research, 45, 36-41. https://doi.org/10.1159/000314720 
[41] Luo, M., Lim, W.Y., Tan, C.S., Ning, Y., Chia, K.S., van Dam, R.M., Tang, W.E., Tan, N.C., Chen, R., Tai, E.S. and Venkataraman, K. (2017) Longitudinal Trends in $\mathrm{HbA1c}$ and Associations with Comorbidity and All-Cause Mortality in Asian $\mathrm{Pa}$ tients with Type 2 Diabetes: A Cohort Study. Diabetes Research and Clinical Practice, 133, 69-77. https://doi.org/10.1016/j.diabres.2017.08.013

[42] Mafauzy, M. (2006) Diabetes Control and Complications in Public Hospitals in Malaysia. Medical Journal of Malaysia, 61, 477.

[43] Afroz, A., Chowdhury, H.A., Shahjahan, M., Hafez, M.A., Hassan, M.N. and Ali, L. (2016) Association of Good Glycemic Control and Cost of Diabetes Care: Experience from a Tertiary Care Hospital in Bangladesh. Diabetes Research and Clinical Practice, 120, 142-148. 